Response to Commentaries on The Impact of Implementing an "Incredible Years" Group Within a Family Living Unit in a Transitional Living Shelter: The Case of "Cathy"

\title{
Further Consideration of Systems, Stigma, Trauma, and Access to Care
}

\section{KAREN C. ROGERS, ${ }^{\mathrm{a}, \mathrm{f}}$ MICHELLE BOBICH, ${ }^{\mathrm{b}, \mathrm{c}, \mathrm{d}}$ \& PATRICK HEPPELL ${ }^{\mathrm{b}, \mathrm{e}}$}

a Keck School of Medicine of USC, University of Southern California

$\mathrm{b}$ USC University Center for Excellence in Developmental Disabilities at Children's Hospital Los Angeles

${ }^{\mathrm{c}}$ Western Youth Services

$\mathrm{d}$ Journeys Counseling Center, Costa Mesa, CA

e Department of Child \& Adolescent Psychiatry at New York University School of Medicine, and Department of Child \& Adolescent Psychiatry at Bellevue Hospital Center, New York, New York

${ }^{\mathrm{f}}$ Correspondence regarding this article should be addressed to Karen C. Rogers, Keck School of Medicine of USC, University of Southern California, 4650 Sunset Blvd Mailstop 53, Los Angeles, CA 90027

Email: krogers@chla.usc.edu

\begin{abstract}
The commentaries by Williams (2016) and Gartenberg and Lang (2016) on the case of Cathy and her mother Ms. Z (Rogers, Bobich, \& Heppell, 2016) explore the similarities between children who have been homeless and those in the foster system, and highlight the importance of traumafocused treatment to address their mental health needs. A further consideration of the challenges to obtaining such treatment due to system barriers, stigma, and the intergenerational transmission of trauma is applied to the case of Cathy. This illustrates the importance of an array of mental health treatment options and the ability to transition from one treatment (an Incredible Years [IY] group) to another (Child-Parent Psychotherapy [CPP]) as opportunities to increase access to needed care for marginalized families.
\end{abstract}

Key words: "Incredible Years" Program; children; Latina children; homelessness; externalizing behaviors; homeless residence; case study; clinical case study

\section{INTRODUCTION}

In their careful commentaries of Cathy's case study, Williams (2016) and Gartenberg and Lang (2016) highlight barriers encountered by families facing homelessness as well as provide promising future development to better serve marginalized populations.

More specifically, while Williams (2016) focuses on the mental health needs of homeless families with young children, Gartenberg and Lang (2016) highlight similarities between families facing homelessness and those confronted by the child welfare system. In line with Rogers, Bobich and Heppell (2016), both commentaries consider the use of evidence-based 
practices with trauma-informed adaptations as the vehicle to address the needs of families with young children dealing with homelessness and those entering the child welfare system.

Both commentaries offer thoughtful reflection on the multiple, complex and interrelated systemic and intrapsychic factors that can impact mental health care for families of young children who face extreme social adversity. There is a markedly increased awareness in the field of the consequences and pervasive impact of trauma exposure in childhood and a growing scientific understanding of effective trauma treatment for children. These are positive developments towards increased access to effective care for children who have experienced instability and adversity. This is a diverse and complex population that will be best served by a diverse array of treatment options.

Systems barriers and stigma can impede access to care for disadvantaged children and families. The intergenerational transmission of parental trauma can negatively impact families who may have limited awareness of the transmission and can increase mental health symptoms in families. Stigma can also be a strong factor in caregivers' and children's reluctance to enroll in treatment and can impact their level of engagement if they do enter therapy. Using a strengthsbased, trauma-informed framework, we consider the role of these factors on Cathy and her mother, and the benefit of having multiple "doorways" into the trauma-focused therapy that Williams so clearly recommends.

\section{Homelessness and Foster Care}

Homelessness impacts a large number of families each year with a staggering 206,286 people in families with children experiencing homelessness on a single night in January 2015 (National Alliance to End Homelessness, 2016). Additionally a large number of children experience removal from their home, with 415,129 children recorded to be in foster care on September 30th, 2014 (Adoption and Foster Care Analysis and Reporting System, 2014); and thirty-nine percent of these children were 5 years old and younger. As stated by Gartenberg and Lang (2016), families with young children face commonalities, whether they are facing homelessness, are part of the child welfare system or in some cases involved with both systems. Families experiencing these conditions face multiple challenges and are at increased risk for psychosocial difficulties. Moreover, many of the same barriers in accessing appropriate mental health services challenge families coping with homelessness and families involved in the foster care system in similar ways.

\section{Barriers to Accessing Evidence-Based and Trauma-Informed Mental Health Care}

Deeper perception of the obstacles commonly experienced by families struggling with homelessness and families involved in the child welfare system is fundamental in consideration of addressing their specific needs. Multiple obstacles impede families' access to appropriate care. Some hindrances stem from perceptions families have of the service system or themselves, while other barriers are more systemic in nature. As barriers often coexist and continuously interact with each other, it is difficult to present them as separate independent contributors to family accessing care. Families with negative past experiences in systems may have projected a negative view on systems as a whole, for example, if a family had their child removed from their 
Further Consideration of Systems, Stigma, Trauma and Access to Care

K.C. Rogers, M. Bobich \& P. Heppell

Pragmatic Case Studies in Psychotherapy, http://pcsp.libraries.rutgers.edu

Volume 12, Module 2, Article 4, pp. 139-157, 06-29-16 [copyright by author]

care or have seen other families with this situation, they could see helping systems with a skewed view and approach services with hesitancy and distrust. A variety of treatment options within a service system increases the opportunity for children and families to find a "doorway into" treatment that is less difficult for them to enter and find their way to effective, trauma-focused treatment.

\section{Accessing Care: Systems Issues.}

A family's willingness to engage with service systems may be impacted by past negative experiences, the failure of those in a helping role to identify their complex needs, and the complexity and fragmentation of the service delivery systems themselves. Many families of traumatized children have had past experiences with social services systems and other public and private organizations which inform their present access. Past negative experiences and confusion about the norms of different helping agencies can have a significant impact on their attitude about receiving help.

Many families feel they have been wronged by the "system," or that the system has not responded adequately to their needs in the past. Thus, experiences with previous landlords, law enforcement, and court systems may shape their views and lead to mistrust of other systems. Many agencies include a necessary combination of authority figures and support, such as a shelter providing a desperate family with a place to live but also requiring them to meet demanding program expectations, or child protective services removing a child from their parent's care and then helping the parent to reunify with their child. Parents may therefore have an understandable reluctance to trust providers to lend a helping hand without the professional imposing additional requirements upon them (Owens, 2002).

This caution may be magnified by caregiver's past experience of trauma and current depressive symptoms, leading them to deliberate or unintentional avoidance of seeking help and/or unawareness of personal benefits from engaging in mental health services. Beyond avoidance, families may hold real fear to be identified by others who either have mistreated them or may judge them. For example, one of Cathy's mother's neighbors who was identified as a possible candidate to participate in the group refused to sign a consent for videotaping the session, an IY requirement for the supervision of co-trainers, due to fear that the abusing father of her daughter could identify her location because of the video. Her goal was to protect herself and her daughter from a very real threat of harm, but her suspiciousness extended to a context where the risk was exceedingly small.

Outreach, engagement, and referral are crucial in identifying families in need and connecting them to mental health services. However, due the lack of inadequate screens and needs assessments at prenatal care appointments, pediatrician visits, schools, and mothers' own health appointments, families' needs too often remain undisclosed and unidentified. Even when established in a homelessness transitional shelter which provided services to families, Cathy's mother expressed reluctance in participating in mental health services for herself and her family. After intensive outreach by clinicians and shelter staff, Ms. Z. reticently participated in the intake session. Nonetheless, when asked about her own trauma history and symptoms, Ms. Z. strongly questioned, "Why is this important?" 
Other barriers impeding access to care are the fragmentation in service systems and requirements put forth both by the child welfare system and the homeless shelter. Child and adolescent mental health services are often separate from adult mental health clinics, with distinct clinicians having different expertise and rarely providing comprehensive and easily accessible care for the whole family. Developmental services, medical care, substance abuse, child welfare, homeless services, and programs to meet basic needs of low income families (e.g. SNAP, Section 8) all have different locations, requirements, procedures, and norms regarding the role of providers and clients. This makes coordinating across multiple systems a daunting task (Children's Defense Fund). Regulations in place to protect clients, such as HIPAA confidentiality requirements, can be a barrier to collaboration across systems.

Even when programs intend to address the needs of children experiencing adversity, the strategies used may not be evidence-supported. For example, caregivers involved in the child welfare system may be required to attend parenting classes, amongst a long list of other requirements, in order to take steps forward reunification. Like many mothers living in a homeless shelter, and like many caregivers entering the foster care system, Cathy's mother was required to attend a parenting class to maintain her residency in the transitional shelter. However, these parent training classes are often curriculum-based, offered to parents without their children, and may require or include separate childcare. Thus, they lack a dyadic component which can directly address the caregiver-child relationships, the foremost component to mental health and intervention (Lieberman, 1998). Early childhood mental health is still considered a relatively new genre in mental health services. Likewise, as pointed out by Gartenberg and Lang (2016), supervised or unsupervised visitations of children who are separated from caregivers do not provide the caregiver with the guidance or structure needed to ameliorating the caregiver-child relationship.

\section{Initiating and Maintaining Evidence-Based and Trauma-Informed Care}

The nature of homelessness and foster care both yield displacement, transition, and transience, all creating further barriers to initially establishing care and maintaining consistent services. Mental health agencies may be reluctant in initiating ongoing care when a family lacks a permanent address and/or a child is placed in an emergency/temporary foster home. Similarly, if services are initiated, premature terminations due to placement issues create disruptions in services (Agosti, 2013). Even when engagement in services and placement or housing is secured, high clinician turnover presents another source of instability for families (Hopkins et al., 2010).

When mental health services are accessible and available to families, families still encounter challenges. In many mental health systems there is a shortage of existing evidencebased practices focused on trauma and treating young children. This is true for both families with young children involved in child welfare and/or faced with homelessness. (Grayson, 2012; Children's Defense Fund). In her survey of the applicability of evidence-based mental health treatments for children, Fraser and her colleagues (2014) identified only four treatments that were reported to be purposely created for foster care youth. Only two of those had evidence from a randomized clinical trial using foster children, and two only of the four being designed for young children. Other child mental health treatments not designed for foster youth have been evaluated for their use with foster care youth, which will be discussed in a later section. 
Trauma and depression are vastly over-represented in homeless mothers and mothers who are involved in foster care. Ninety percent of homeless mothers have experienced trauma (DeCandia, 2013), while rates of depression range from 45\%-85\% (Bassuk et al., 1996; Bassuk, Buckner, Perloff, \& Bassuk, 1998; Weinreb et al., 2006). Similarly, exposure to multiple traumatic experiences and depression are common in mothers of young children in foster care and remain a significant risk factor for child maltreatment (Banyard, Williams, Siegel, 2003; Cohen, Hien, \& Batchelder, 2008; Kotch, Browne, Dufort, \& Winsor, 1999). However, for reasons mentioned above, these frequently remain undisclosed by caregivers, unidentified by care providers, and therefore untreated.

Meanwhile, many mental health agencies struggle to incorporate and maintain evidencebased treatments in their service options due to lack of funding resources to acquire trainings and certifications for their staffs, which are costly and time consuming. Even when training in evidence-based treatments is acquired by the agency clinicians and delivered to families, retention of staff presents another challenge. That is, when losing staff, the agency has to replace the clinician and train new clinicians quickly (Fraser et Al., 2014) leading to a disruption in services. Practical realities for services providers often influence and dictate which types of treatments are offered and chosen for families, rather than relying on the family's needs or preference.

These practical realities were also influential in the case of Cathy. As part of a larger community mental health center with psychology internship and psychology fellowship training programs, we had opportunities to select from several evidence-based practices. Other smaller mental health agencies may rely on shorter lists. Even in our center, despite having a variety of available evidence-based practices, these modalities are selected and approved by the county's department of mental health services, potentially eliminating other practices suitable for Ms. Z.'s family. The intervention models available to us ranged from Parent Child Interaction Therapy (PCIT), a dyadic approach designed to address children's externalized behaviors, which has shown efficacy at reducing trauma symptoms in children; Trauma-Focused Cognitive Behavioral Therapy (TF-CBT), a model designed to reduce trauma and other symptoms in children, which allows work with the child and caregiver(s) separately and together; Positive Parenting Program ("Triple P"), a parenting program that works solely with the caregiver; and Child-Parent Psychotherapy (CPP), as described by Williams (2016), a dyadic model which aims at strengthening the caregiver-child relationship in the context of their past traumatic experiences. It could be argued that all of these models would have been appropriate for Cathy and Ms. Z., given their trauma history, Cathy's externalized behaviors, and Ms. Z.'s need for enhanced parenting skills.

In Cathy's case, despite access to many suitable evidence-based services including trauma-focused and family-based options, practical and structural issues drove the selection of the Incredible Years Programs. The shelter required a parenting class for the mothers who lived there, and requested that this be provided through the service agreement with the community mental health center. The shelter staff was concerned about what they perceived as a high rate of externalizing behaviors among the resident children (although clinicians identified more internalizing problems when they completed individual assessments). The center's funding through Medicaid was undergoing a significant transformation to require a large portion of 
funded treatment to utilize any of nine identified evidence-supported treatments. The training programs in the community mental health center had previously invested in developing the capacity for training in the IY program, so training was readily available to the group leaders. And finally, the group was to be provided to residents of the longer-term transitional program (up to two years) rather than one of the shelter's shorter-term programs, meaning that residents were available to participate in a group program that was 22 weeks long.

While practical realities influenced the decision to implement the IY program at the shelter, it is important to note that the clinicians were strongly committed to provide effective, evidence-based treatments as a part of the community mental health center's service and training mission to provide quality care to an underserved, urban population.

Many of these barriers faced by families stem from the stigma attached to mental illness, homelessness, and being involved in child welfare. In addition, families continue to experience distress and symptoms of trauma even while receiving services. As in the case of Cathy, there is a limited mental health system capacity to treat and identify intergenerational, trauma-related issues due to time and resources. Families like Cathy's face multiple stressors and hardships, including past trauma, homelessness and intergenerational trauma. Access to trauma-informed care to treat these issues in both the caregiver and child in coherent, simultaneous and efficacious ways are limited from a system and agency perspective and also due to barriers of accessing care. One of the areas that serve as a barrier to receiving treatment is the burden of stigmatization.

\section{STIGMA}

Children and families who have experienced homelessness, like children in foster care, face many practical and systemic barriers to care. They also face significant stigma barriers, both external and internal, which may serve both to worsen mental health and to impede access to care. External forms of public stigma reflect reactions that the general public has towards individuals with specific conditions, resulting in discrimination and social distancing. Selfstigma refers to the internalization of negative stereotypes towards oneself, and the resulting demoralization (Corrigan \& Watson, 2001). The interaction between public stigma, the responses one receives from others in the environment, and the negative view of oneself stemming from self-stigma can reduce the likelihood of referrals for mental health treatment, willingness to follow through on recommendations, and level of engagement in treatment. Families experiencing homelessness or child welfare involvement are members of stigmatized groups who may be particularly resistant to situations, including participation in mental health treatment, which could further stigmatization. Multiple, non-stigmatizing opportunities to enter treatment maximize the likelihood for a child to be able to receive effective trauma-focused treatment to ameliorate the impacts of homelessness or foster care.

Public stigma associated with mental illness, which extends beyond the general public to trained mental health professionals, contributes to a significant lack of available treatment resources, housing and employment discrimination, and social distancing (Corrigan \& Watson, 2002). Public stigma towards people with mental illness is not limited to adults. Children with mental illness are subject to negative stereotypes and discrimination towards themselves and 
their families (Mukolo, Heflinger \& Wallston, 2010). Public stigma also reduces the likelihood for adults and children to be referred for mental health care by physicians and other helping professionals (Bitar et al, 2009), and for parents to report shared decision-making with their child's primary medical provider related to the need for mental health care (Butler, 2014). Ms. Z's initial reluctance to enroll her children in mental health care can be understood as an awareness of potential for discrimination and rejection for both her daughters and for herself as a mother.

The risk of stigma may have been particularly acute for the $\mathrm{Z}$ family, whose history of homelessness and ongoing instability subjected them to the negative appraisals of others. As Gartenberg and Lang (2016) point out, children who have experienced homelessness and those in the foster system face similar levels of trauma and instability, contributing to a need for, and significant barriers to, mental health care. Both populations are also subject to stigma, which impedes access both to needed mental health care and to social support that could mitigate the stress associated with homelessness or foster placement. Public stigma towards homeless adults has been linked to discrimination and social distancing (Phelan et al., 1997). Similarly, homeless adolescents face significant and pervasive, but less studied, public stigma (Kidd, 2009).

Children who have experienced homelessness face discrimination, blame and rejection of their caregivers, and may also face discrimination in their communities or schools (FonfieldAyinla, 2009). There is less research literature on stigmatization of children in foster care, although both foster youth and foster caregivers identify such stigma (Buchanan, 1995, Blythe et al., 2012). Public stigma may contribute to the dire shortage of foster homes in many states, as families are reluctant to take the risk of inviting a foster child into their home. In addition, negative views of children and families involved in the child welfare system may lead to a shortage of resources to address the complex needs of the children.

Kennedy, Bybee, and Greeson (2014) offer a conceptualization of how public stigma can impact mental health of youth. Exposure to an abusive family context can engender feelings of worthlessness and shame, which may be confirmed or increased by experiences of discrimination due to stigma. In addition, the stress of stigmatization may be a reminder of rejection by abuse by family members, thus triggering trauma symptoms. Finally, youth experiencing discrimination may need constant vigilance to protect themselves and have their needs met, magnifying the hyperarousal symptoms of PTSD. Ms. Z's depression may have been a result of both her personal trauma history and her significant experience of stigma through four different shelter placements and rejection by her family.

In addition to the negative impacts of public stigma, self-stigma can have a significant effect on engagement in mental health care. Self-stigma is a barrier to seeking information about mental health (Lannin et al. 2015), increases the risk of sexual problems and dating violence following sexual abuse, and impacts a child's ability to engage in constructive processing of sexual abuse in treatment (Simon, Fiering, \& Clelland, 2014). Self-stigma extends to parents of children in need of mental health care (Young \& Rabiner, 2015). Ms. Z's negative self-image may have been exacerbated by a view of herself as depressed and unable to benefit from treatment. Seeking mental health care for herself or her child would have meant taking on the additional stigma of mental illness. 
For Ms. Z., the stigma of domestic violence and homelessness and repeated experiences of rejection and discrimination, as evidenced by her lack of family support, likely negatively impacted her sense of her worthiness and ability to maintain a safe and stable home for herself and her family. Faced with a child whose externalizing behaviors may have seemed like a threat to her family's stability, Ms. Z responded with the same blame and distancing that she herself experienced. Refusing mental health treatment when it was initially offered for her children may have been an important self-protective strategy to avoid worsening her own depression through additional internalized negative self-attributions and experiences of rejection. In addition, Ms. Z may have been seeking to limit the stigmatization of her children as mentally ill.

A number of components of the IY parent and child groups offered at the shelter provided opportunities to counteract Ms. Z's sense of stigma, increasing her receptiveness for continued trauma-focused treatment for her children and herself. These include both structural aspects, such as locating the group outside the community mental health center and making it required for all families regardless of diagnosis; and the trauma-informed adaptations that the group leaders utilized.

Providing the IY Group to all shelter residents in fulfillment of the program requirement for a parenting class was a significant step in reducing mental-illness-related stigma for the families. It is important to note that there were multiple strategies used to introduce the group to the shelter residents and engage them in the program; ultimately it required significant personal outreach to each mother to enroll the families into the group program.

Group leaders' use of trauma-informed care strategies of collaboration and empowerment provided a counter-example to the discrimination and shame group members may have experienced in other contexts. While the mothers reported that completing the DAPS, which documents post-traumatic stress, was overwhelming and painful for them, it did open the door for the group leaders to provide psychoeducation on the impact of trauma, normalizing and reducing the shame associated with the participants' past experiences. Visiting with the Z family in their home to support Ms. Z's use of new skills was an opportunity to strengthen the relationship between the group leaders and the family and to communicate respect for Ms. Z's ability to provide a good home for her daughters.

With Cathy identified as the "problem” in the family, the child group leaders' expectation that Cathy could succeed, and willingness to make changes to the program to support Cathy's success modeled a different understanding of Cathy's behaviors. Ongoing positive feedback to Ms. Z about Cathy's participation and the inclusion of goals for her older sister Yvette's participation in the group may have further reduced Cathy's identification as stigmatized. This changing view of Cathy increased the potential for positive and warm interactions between her and her mother and sister. Facing reduced stigma and an improved attachment relationship may have contributed to Cathy's increasing ability to use positive behaviors both within and outside the group setting. Over time, Cathy's risk of self-stigma was reduced as a result of the group treatment.

Finally, the graduation celebration with its emphasis on the accomplishments of both mothers and children and anticipation of future successes for the family was a powerful 
counterpoint to stigma. No longer undeserving, incompetent, or bad, the children and families were able to anticipate being worthy of future success and recognition. Indeed, one of the mothers who never expected to see herself or her son graduate from anything reflected that changed sense of self-stigma when she anticipated seeing him graduate from high school.

We agree with Dr. Williams that children who have experienced toxic stress and early trauma benefit most from trauma-focused treatment. We believe Ms. Z's initial reluctance to seek mental health care for her children in part reflects the impact of mental illness stigma experienced by many parents. This stigma may be intensified for families who feel that they failed in their duty to protect their child from harm, resulting in the child's trauma exposure, experience of homelessness, or placement in foster care. Compounding this is the fact that homelessness and foster placement themselves carry stigma, and the intergenerational impacts of trauma. Offering a variety of entry points into mental health care is an important way to reduce the barriers associated with stigma. For the Z family, a parenting class required for all residents in their community was the entry point. For others families, care integrated into other service settings such as primary care or school may be more accessible. Similarly, opportunities to transition from early intervention to trauma-focused mental health treatment may be especially valuable for families from marginalized groups.

\section{INTERGENERATIONAL TRAUMA}

The environment and parental figures of a child are central to their social learning, which directly influences their behaviors. As we review the case of Cathy, we see there are many confounding factors that contributed to the family conflict, maternal depression, attachment disruption, and Cathy's externalizing behaviors. As discussed in Dr. Williams' (2016) commentary, the chronic depression of Ms. Z and the prenatal intimate partner violence she experienced highlight the potential for intergenerational trauma.

The impact of intergenerational trauma in families who have experienced traumatic events and life stressors is an important factor to assess when conceptualizing and treating children and families with early exposure to intimate partner violence, a parental history of trauma, exposure to maternal mental illness, and a history of homelessness. We will be looking at this through a trauma lens to better understand the needs of Cathy and Ms. Z as a way to highlight needs for others in this situation as well as to highlight treatment approaches and to promote awareness of intergenerational trauma impacts.

The transmission of intergenerational trauma has been well documented in studies discussing the "Holocaust syndrome" or "survivor syndrome," as described by Nederland (1961). Since this awareness, several hundred articles on intergenerational transmission have been published to further evaluate what may be transmitted to the second generation of trauma survivors. More recent studies have focused on the impact of parental trauma being passed to their children. The importance of this subject has also been recognized by the International Society of Traumatic Stress Studies (ISTSS), with the founding and maintaining of a Special Interest Area Group on Intergenerational Transmission of Trauma and Resiliency. Due to Ms. Z's trauma history it is important to look at how the transmission of trauma symptoms may have impacted the attachment, parenting and overall relationship with Cathy. 
With 1 in 15 children being exposed to intimate partner violence each year, and 90\% being eyewitnesses to this violence, the case of Cathy does not stand alone. Many children experience traumas either by eyewitness accounts, possibly through transmission of parent behaviors as understood through social learning as well as through intense exposure to stress hormones in utero. The experiences children have prior to the development of language can be easily overlooked during assessments or in parent or child report, but have a significant impact on the child's emotional well-being.

\section{Intergenerational Trauma Theory}

Two perspectives are often sited to promote understanding of what is known as the resilience perspective and the vulnerability perspective. The resilience perspective holds that children of survivors who are able to cope with their traumatic experiences will have increased resilience when encountering future trauma. On the other hand, the vulnerability perspective holds that "permanent psychic damage" of trauma leaves children of survivors more vulnerable to future negative impacts of trauma (Danieli, 1998).

Evidence for both of these perspectives emerges when applied to the case of Cathy. Cathy's mother, Ms. Z, experienced previous traumatic experiences prior to becoming a mother. This could have primed her for being more vulnerable to the cycle of violence and being in an unsafe relationship resulting in intimate partner violence with two young children. Beliefs about the world and interpersonal relationships that Ms. Z formed as a result of her trauma exposure could have been passed on to Cathy and Yvette through social learning. However, Ms. Z also demonstrated resilience and courage to change her situation by leaving the violent relationship, a potent example for her daughters of self-protection and strength. Recognizing Ms. Z's history and propensity for becoming vulnerable to more trauma, her act of courage in seeking help could be easily overlooked.

\section{Theories on the Transmission of Trauma}

Weingarten (2004) categorizes transmission of intergenerational trauma effects into four categories: biological, psychological, familial, and societal. The biological perspective is based on studies that show a second generational vulnerability to PTSD possibly due to lower cortisol levels. Psychologically, in evaluating the case of Cathy, Ms. Z experienced symptoms of depression and symptoms of PTSD. Due to the evaluation being primarily for Cathy and her sibling, the mother was not evaluated diagnostically. However, she self-reported a history of depression. Ms. Z's trauma symptoms impacted her ability to be supportive and understanding of Cathy's behavior. As for the familial perspective, we can see how the transmission of trauma could have been impacting the family through the reactivity of Cathy toward Ms. Z and of Ms. Z toward Cathy. Finally, from a societal perspective, Ms. Z expressed not trusting other members of the group and keeping to herself intentionally. This type of parental behavior, as understood through social learning theory, likely impacted Cathy's socialization, adding to Cathy's mistrust, suspiciousness and safety concerns when interacting with others. 
Another perspective is offered by Ancharoff, Munroe, and Fisher (1998) who developed a working model referred to as secondary trauma, in which a parent's "traumatized worldview" can be learned or transmitted through the parent-child relationship. Four primary mechanisms for this transmission are noted as: silence, overdisclosure, identification, and reenactment. In the Z family, past difficult and frightening experiences were never discussed. Ms. Z's avoidance of this topic stemmed from her own past trauma history, and demonstrated to her daughters that such things were unspeakable. At the same time, Ms. Z had difficulty recognizing what issues were not appropriate to discuss at length with her children. During the home intervention adaptation for the group, there were focused discussions on how to limit the sharing of financial burdens, unemployment, information on other members of the shelter being asked to leave for various reasons, and overall sharing of parental stress as to limit the transmission of parental or environmental stress to Cathy. Ms. Z perceived Cathy as behaving "just like her father" who had been abusive towards her. This identification lead her to distance herself from Cathy and impacted her ability to understand the roots of Cathy's behaviors. Some of Cathy's reactions to Ms. Z demonstrate the transmission of trauma through reenactment as she witnessed verbal, physical and emotional abuse from her father toward Ms. Z. Cathy had externalizing and aggressive behaviors toward Ms. Z as well as issues of noncompliance, tantrumming and aggressive behaviors. It's possible that Cathy was, through social learning and transmission of trauma, reenacting what she had seen from the intimate partner violence she had witnessed.

\section{PARENTING AND ATTACHMENT}

Caregivers with difficulties regulating emotions can struggle to use effective parenting practices in ways that negatively impact their children. In the case presented for Cathy, Ms. Z reported one major traumatic event in her early life in addition to the intimate partner violence she experienced. These experiences alone can create high stress and impact functioning. Ms. Z experienced many other stressors, including homelessness, caring for two young children with minimal support, unemployment, an estranged family, and mental illness (self-reported as depression, although she was not evaluated from a formal diagnostic perspective). When a family is impacted by high stress and exposure to multiple traumas, relationships between parent and child, and between siblings, can be negatively impacted.

As noted by Dr. Williams, there are many adverse outcomes to attachment relationships when infants are exposed to intimate partner violence. Parents with histories of complex trauma often have difficulty with emotional regulation (van der Kolk, B.A., McFarlane, A.C., \& Weisaeth, L., 1996). The role of parental trauma exposures and the child's experience and functioning continues to be an area of important study. One study found that the children of caregivers with unresolved loss histories have increased behavior problems (Zajac \& Kobak, 2009). The lack or loss of self-regulation is a well researched impact of psychological trauma in both children and adults.

As seen in the interactions of Cathy and Ms. Z, their trauma reactions toward each other were activating continued attachment injuries and causing attachment disruptions. Ms. Z and Cathy appeared to be triggering the other, resulting in less safety in the relationship. Ms.Z demonstrated a difficult time regulating her emotions when triggered by Cathy's behaviors, seeing her as being “evil” and Cathy possibly viewing her mother as unsupportive and 
misunderstanding her acting out behaviors due to her limited capacity for regulating emotions. A parent with dysregulated affect can be unpredictable and frightening for a child. The parent-child relationship as a whole becomes colored by a lack of safety and mutual trust. As seen throughout this case, the impact of intergenerational trauma and attachment disruptions are important factors to address in formulating a plan to help the family improve relational interactions.

This traumatized world view may also influence a parent's willingness to engage in mental health services for herself and her children. In a world perceived as unsafe and unpredictable, allowing strangers access to information about herself and her children may have seemed dangerous to Ms. Z, who demanded to know "Why is this important?" when asked by a clinician about her own trauma history. Attachment theory holds that lessons learned from primary attachment relationships are generalized to others. To the extent that Cathy and Ms. Z viewed each other as threatening (Cathy to act like her mother's abuser, and Ms. Z to respond harshly to Cathy's behavior), they would be likely to expect the same from other relationships. Cathy's initial guardedness and reluctance to join the group may have resulted from her anticipation of a critical response from group leaders as well as her lack of experience in a structured group such as preschool.

\section{POSITIVE FUTURE DEVELOPMENTS}

In consideration of barriers mentioned above, especially those related to intergenerational trauma and stigma experienced by Cathy's family and experienced by families involved in the child welfare system and/or faced with homelessness, we discuss promising future developments and considerations to best serve the unique needs of marginalized families with young children.

\section{General Guidelines}

Although trauma-informed practices and early childhood mental health interventions are considered relatively new fields in psychology and psychiatry, both are receiving national attention and rapidly emerging as relevant and central practices in understanding marginalized populations and providing appropriate care.

For example, useful and comprehensive guidelines as provided by nationally recognized agencies as well as by states, counties and mental health agencies are readily available and accessible. Existing and continuously growing lists of resources are available online for caregivers, individual providers, agencies, and stakeholders to support the work of implementing trauma-informed practices. This is true for working with children and families involved in child welfare and homeless families with young children. Trauma-informed guidelines are made available by the Federal National Child Traumatic Stress Network (NCTSN; http://www.nctsn.org) for individual providers working with children and their families in their Child Welfare Trauma Training Toolkit: Comprehensive Guide-2nd Edition. This Guide specifically delineates the following essential elements of trauma-informed care: (1) Maximize the child's sense of safety; (2) Assist children in reducing overwhelming emotion; (3) Help children make new meaning of their trauma history and current experiences; (4) Address the impact of trauma and subsequent changes in the child's behavior, development, and relationships; (5) Coordinate services with other agencies; (6) Utilize comprehensive assessment 
of the child's trauma experiences and their impact on the child's development and behavior to guide services; (7) Support and promote positive and stable relationships in the life of the child; (8) Provide support and guidance to the child's family and caregivers; and 9) Manage professional and personal stress. Similarly, NCTSN also provides specific guidelines for agencies working with youth and families in child welfare. Their recommendations specifically describes the following: (1) Knowledge Building and Developing Practices; (2) TraumaInformed Mental Health Assessment; (3) Case Planning and Management; (4) Externally Delivered, Trauma-Informed Services; and (5) Child Welfare Systems, Cross-System Partnerships, and System Collaboration.

Similarly, also available are guidelines for homeless families with young children, which speak to addressing identified barriers. The guidelines were collated by the American Institute for Research and the National Center on Family Homelessness (Bassuk, DeCandia, Beach, \& Berman, 2014). These guidelines include: (1) Provide safe and affordable housing; (2) Offer education and employment opportunities; (3) Conduct comprehensive assessments of all family members; (4) Provide trauma-informed care; (5) Prevent, identify, and treat major depression in mothers; (6) Provide parenting supports; (7) Provide developmentally appropriate services for children in transition; and (8) Develop and fund a comprehensive research agenda.

\section{Evidence-Based Mental Health Practices}

There are a growing number of evidence-based treatments applicable for children in foster care. As discussed earlier, only four evidenced-based treatments for children have been designed specifically for youth in foster care (Baker et al., 2013). However, in their same survey Baker and colleagues (2013) identified 22 treatments, all of which were evaluated in a randomized control trial designed with foster care children in the sample. Six of these, including the Incredible Years program, addressed all 10 elements recognized as essential in treating children in foster care and are proving effective in reducing PTSD symptoms for children in foster care. Moreover, 11 other evidence-based treatments that were not created specifically for youth in foster care nor evaluated with this population appear to address all ten essential components and warrant further evaluation with this population. In summary, more evidencebased practices for children are being evaluated in their applicability and efficacy to address the needs of children in foster care, widening the pool of available practices to providers and families.

Deviating from a manualized treatment is tricky, risky and at times needed in clinical and "real world" settings. When considering the use of evidence-based practices with children in foster care, in order to assure appropriate spread and sustainability, Fraser and colleagues (2014) caution to consider "sufficient fidelity" to the chosen model versus often-needed adaptation to the curriculum for implementation in the "real world." As discussed by Gartenberg and Lang (2016) and Williams (2016), the use of the Incredible Years programs in a homelessness shelter required both fidelity to the model and the constant use of flexibility and small adaptations, which, in the end, allowed for Cathy and her mother to have access, participate and benefit from the evidence-based intervention. 
Promising new evidence-based approaches specific to homeless families are likewise available. Three cost-effective, parenting intervention approaches supporting families and young children are particularly important to note. First, Parenting Through Change (PTC) has shown high retention and participant satisfaction both in an emergency domestic violence shelter setting (Gewirtz \& Taylor, 2009) and in supportive housing agencies (Gewirtz, 2007) by targeting five parenting practices: skill encouragement, problem-solving, limit setting, monitoring, and positive involvement. Second, the Family Care Curriculum (FCC) is designed for women with children who are living in emergency and transitional housing (Hudson \& Sheller, 2016) and has increased mothers' sensitiveness and receptiveness to their children's needs, resulting in behavioral changes over time by including Effective Black Parenting, and trauma-informed care. Third, Family Talk (Beardslee et al., 1998) is highly rated by the Federal Substance Abuse and Mental Health Services Administration (SAMHSA) for its ability to improve parental responsiveness and skills for families experiencing homelessness and parental depression.

\section{Individualized Evidence-Based Practices?}

Like many mothers involved in child welfare systems and/or mothers faced with homelessness, Ms. Z. experienced traumatic experiences and depressive symptoms. Furthermore, she experienced a diminished sense of control and self-efficacy given her past experiences, her current symptoms, her daughter's symptoms seen as the result of her own poor parenting skills, a current temporary living situation, and having an array of requirements placed upon her. While considering these contributing factors and barriers, we view the use of choice as an important element in her treatment. Thus it is necessary in cases like Cathy's not only to initiate outreach and engagement, but also to increase clients' participation by addressing their mental health issues and other needs, all while increasing the mothers' sense of empowerment, a positive prognostic predictor and underlying vehicle for change.

Cathy and her mother experienced multiple challenges and barriers. Themes of intergenerational trauma, stigma, and homelessness transpire across their experiences of accessing care and participating in services. Williams (2016) discusses potential benefits for working with Cathy and her mother directly together in the context of their past traumatic experiences. Although multiple evidence-based interventions previously described were accessible through the community mental health center, Ms. Z. declined any mental health services for herself at the time of intake. Being mandated to the required "parent group" and the "child group" associated with the evidence-based Incredible Years programs fulfilled the requirement put forth by the homeless shelter. The trauma-informed adaptations provided in both programs were designed to reduce Ms. Z's suspiciousness and to increase her awareness of the benefits of mental health services for herself and for both of her daughters. This nonstigmatizing, trauma-informed, parenting-focused experience may have opened many doors for Ms. Z toward receiving help in the near and far future.

In deciding which approach would "work best” for Cathy and her family, whether during the outreach and engagement phase, at the time of intake, or after her participation in the IY group, what if during the process Ms. Z. was provided with several therapeutic models to choose from? In collaboration with her case worker at the homeless shelter and the clinician, Ms. Z. may have engaged in the decision-making phase and discussed: her own needs; her children's needs; 
her preference as far as individual, dyadic and/or group formats; her preference for keeping her own treatment separate from her children's treatment; her readiness for participation in trauma treatment versus parental skills; her desire to receive services within the homeless shelter versus traveling to an outside agency. All the while during this process, the relevant clinicians would have to assure that the decisions Ms. $\mathrm{Z}$ made fulfilled the requirements of the homeless shelter.

Working in partnership early on with Ms. Z, especially during the decision-making process, may have allowed Ms. Z. to feel valued and to be able to drive decisions about her own care and the care of her children. This would be in contrast to Ms. Z feeling imposed upon by the system and feeling like she was unable to know what was best for her and her own children. Choice may offer a pathway to destigmatization and an opening to tackle intergenerational trauma for marginalized families. Lastly, it would have answered Ms. Z's initial question during intake when asked about her own trauma and symptoms: "Why is this important?"

Similarly, choices may be provided to caregivers involved in the child welfare system to select services that may best fit their needs and preference during the reunification phase. Giving a voice and empowerment to caregivers who have faced multiple adversities may increase their participation and retention in services. Because families may initially have difficulty recognizing or understanding the role of past trauma in the development and maintenance of mental health symptoms, the array of service options should include other effective prevention and intervention services. As the $\mathrm{Z}$ family demonstrates, a positive experience with a traumainformed (rather than trauma-focused) approach may decrease families' reluctance to engage in more trauma-specific treatment. Such a family experience can also positively impact outcomes, such as a reduction in symptoms, an improvement in parenting skills and in a parent's relationship with their children, adjustment to a new residence, and steps taken toward reunification with their children. Further, limitations on the types or number of intervention programs a family is eligible for should be avoided so that families may progress from parentingfocused and resiliency-building approaches to trauma-focused treatment, or vice versa, depending on individual preferences.

In light of the above, it is important to increase the availability and dissemination of evidence-based mental health approaches for families and children involved in the child welfare and/or for families with children facing homelessness. Involving the caregiver in deciding their next steps in terms of treatment, when available and appropriate, may pave the way for further exploration and evaluation of choice as it relates to participation, retention and mental health outcomes.

Some of the many factors necessary for the possibility of providing choices to marginalized families include: reliance on provided guidelines; increased funding to provide training for clinicians in evidence-based mental health practices and training for case workers in child welfare settings and homeless shelters; flexibility delivering evidence-based treatments while using adaptations and maintaining sufficient fidelity; partnerships amongst different agencies; and flexibility in terms of requirements put forth by courts, social agencies, child welfare agencies. 
Most importantly, when working with marginalized families — whether wrestling with homelessness, child welfare systems, past traumatic experiences, and/or depressionoverarching stigma can be reduced by believing that mothers and other caregivers want to and can be involved in decision-making and in designing their road to recovery, reunification with their children, and/or the wellness of their family. Remaining aware of the impact of intergenerational trauma and providing treatment options to families that are trauma-informed and family-based may also reduce the stigma of "being a bad mother" who is required to participate in a parenting class by an external authority.

This is not to argue against any requirement to participate in treatment for families connected to social service systems. In fact, Cathy's family presents an example of how a positive experience with required treatment that is also trauma-informed and evidence-based can reduce reluctance to seek further care. A deeper understanding of the multiple barriers experienced by marginalized families help us recognize the underlying factors—such as courage, grit, fear, and protectiveness toward their own children — which often surface as "resistance" on the part of mothers and other caregivers. This greater understanding may also widen our way of thinking as providers about how to conduct engagement and outreach so as to effectively deliver sensitive, individualized, trauma-informed and family-based treatment.

\section{REFERENCES}

Adoption and Foster Care Analysis and Reporting System (AFCARS). (2014) U.S. Department of Health and Human Services, Administration for Children and Families, Administration on Children, Youth and Families, Children's Bureau. Retrieved from http://www.acf.hhs.gov/programs/cb

Ancharoff, M. R., Munroe, J. F., \& Fisher, L. M. (1998). The legacy of combat trauma: Clinical implications of intergenerational transmission. In Y. Danieli (Ed.), International handbook of multigenerational legacies of trauma (pp. 257-276). New York: Plenum Press.

Agosti, J., Conradi, L., Halladay Goldman, J., and Langan, H. (2013). Using trauma-informed child welfare practice to improve placement stability breakthrough series collaborative: Promising practices and lessons learned. Los Angeles, CA \& Durham, NC: National Center for Child Traumatic Stress.

Baker, A. J., Brown, E. L., Schneiderman, M., Sharma-Patel, K., \& Berrill, L. M. (2013). Application of evidence-based therapies to children in foster care: a survey of program developers. APSAC Advisor, 27 (3).

Banyard, V.L., Williams, L.M. \& Siegel, J.A. (2003). The impact of complex trauma and depression on parenting: Exploration of mediating risk and protective factors, Child Maltreatment, 8(4), 334-349.

Bassuk, E. L., Buckner, J.C., Perloff, J. N., \& Bassuk, S. S. (1998). Prevalence of mental health and substance use disorders among homeless and low-income housed mothers. The American Journal of Psychiatry, 115, (11), pp. 1561-1564.

Bassuk, E. L., DeCandia, C. J., Beach, C.A., \& Berman, F. (2014). America's youngest outcasts: A report card on child homelessness. The National Center on Family Homelessness American Institutes for Research. 
Bassuk, E., DeCandia, C., Beach, C., and Berman, F. (2014) America's youngest outcast: A report card on child homelessness. The National Center on Family Homelessness at the American Institute for Research. http://www.air.org/sites/default/files/downloads/report/Americas-Youngest-OutcastsChild-Homelessness-Nov2014.pdf

Bassuk, E. L., Weinreb,L. F., Buckner, J.C., Browne,A., Salomon, A., \& Bassuk, S. S. (1996). The Characteristics and needs of sheltered homeless and low-income housed mothers. The Journal of American Medical Association, 276(8): 640-646

Beardslee W. R., Versage E.M., \& Gladstone T.G. (1998). Children of affectively ill parents: A review of the past 10 years. Journal of American Academy of Child and Adolescent Psychiatry, 37, 1134-1141

Bitar, G. W., Springer, P., Gee, R., Graff, C., \& Schydlower, M. (2009). Barriers and facilitators of adolescent behavioral health in primary care: Perceptions of primary care providers. Families, Systems, \& Health, 27(4), 346-361. doi:10.1037/a0018076

Blythe, S. L., Halcomb, E. J., Wilkes, L., \& Jackson, D. (2012). The stigma of being a long-term foster carer. Journal of Family Nursing, 18, 2, 234-260.

Buchanan, A. (1995). Young people's views on being looked after in out-of-home-care under The Children Act 1989. Children and Youth Services Review, 17(5-6), 681-696. doi: 10.1016/0190-7409(95)00046-f

Butler, A. M. (2014). Shared decision-making, stigma, and child mental health functioning among families referred for primary care-located mental health services. Families, Systems, \& Health, 32(1), 116.

Children Defense Fund. Barriers: Why is it so difficult for children to get mental health screens and assessments? Retrieved from http://www.childrensdefense.org/library/data/barrierschildren-mental-health-screens-assesments.pdf

Cohen, L. R., Hien, D.A. \& Batchelder, S. (2008). The impact of cumulative maternal trauma and diagnosis on parenting behavior. Child Maltreatment, 13(1), 27-38.

Collins, K., Connors, K., Davis, S., Donohue, A., Gardner, S., Goldblatt, E., Hayward, A., Kiser, L., Strieder, F. Thompson, E. (2010). Understanding the impact of trauma and urban poverty on family systems: Risks, resilience, and interventions. Baltimore, MD: Family Informed Trauma Treatment Center. http://nctsn.org/nccts/nav.do?pid=ctr_rsch_prod_ar

Corrigan, P. W., \& Watson, A. C. (2002). Understanding the impact of stigma on people with mental illness. World Psychiatry, 1(1), 16-20.

Danieli, Y. (Ed.). (1998). International handbook of multigenerational legacies of trauma. New York: Plenum Press.

DeCandia, C. J. (2013). Addressing the needs of families experiencing homelessness. The National Center on Family Homelessness at the American Institutes for Research. Retrieved from http://www.air.org/resource/addressing-needs-families-experiencinghomelessness

Fraser, J. G.,Griffin, J. L., Barto, B. L., Lo, C., Wenz-Gross, M., Spinazzola, J., Bodian, R. A., Nisenbaum, J. M., \& Bartlett, J. D., (2014). Implementation of a workforce initiative to build trauma-informed child welfare practice and services: Findings from the Massachusetts Child Trauma Project. Children and Youth Services Review 44, 233-242.

Fonfield-Ayinla, G. (2009). Commentary: A consumer perspective on parenting while homeless. American Journal Of Orthopsychiatry, 79(3), 299-300. doi:10.1037/a0017239 
Gartenberg, A. S., \& Lang, L. R., (2016). Considerations for the dissemination of Incredible Years in welfare systems: Implications of the case of "Cathy" for intervention in the foster care system. Pragmatic Case Studies in Psychotherapy, 12(2), Article 3, 124-138. Available: pcsp.libraries.rutgers.edu

Gerwirtz, A. H. (2007). Promoting children's mental health in family supportive housing: A community-university partnership for formerly homeless children and families. The Journal of Primary Prevention, 28 (3), 359-374.

Gewirtz, A. H., \& Taylor, T. (2009). Participation of homeless and abused women in a parent training program: science and practice converge in a battered women's shelter. In M. F. Hindsworth \&T.B. Lang (Eds.). Community participation and empowerment, pp. 97-114. Hauppage, NY: Nova Science Publishers.

Grayson, J. (2012). Mental health needs of foster children and children at risk of removal. American Psychological Association's Children, Youth, and Families Office Newsletter.

Henry, M., Shivji, A., Sousa, T. \& Cohen, R. (2015). The 2015 Annual Homeless Assessment Report (AHAR) to Congress. The U.S. Department of Housing and Urban Development. Retrieved from https://www.hudexchange.info/resources/documents/2015-AHAR-Part1.pdf

Hopkins, K. M., Cohen-Callow, A., Kim H. J., \& Hwang, J. (2010). Beyond intent to leave: Using multiple outcome measures for assessing turnover in child welfare. Children and Youth Services Review, 32, 10, 1380-1387.

Hudson, K., \& Sheller, S. (2016). The Family Care Curriculum (FCC). Philadelphia: The Children' Hospital of Philadelphia. Retrieved from: http://www.chop.edu/services/familycare-curriculum\#.V3HUPPkrKUk

Kennedy, A. C., Bybee, D., \& Greeson, M. R. (2014). Examining cumulative victimization, community violence exposure, and stigma as contributors to PTSD symptoms among high-risk young women. American Journal Of Orthopsychiatry, 84(3), 284-294. doi:10.1037/ort0000001

Kidd, S.A. (2009). Social Stigma and Homeless Youth. In: Hulchanski, J. David; Campsie, Philippa; Chau, Shirley; Hwang, Stephen; Paradis, Emily (eds.) Finding Home: Policy Options for Addressing Homelessness in Canada (ebook), Chapter 3.5. Toronto: Cities Centre, University of Toronto. www.homelesshub.ca/FindingHome

Kotch, J. B., Browne, D. C., Dufort, V., \& Winsor, J. (1999). Predicting child maltreatment in the first 4 years of life from characteristics assessed in the neonatal period. Child Abuse \& Neglect, 23 (4), 305-319.

Lannin, D. G., Vogel, D. L., Brenner, R. E., Abraham, W. T., \& Heath, P. J. (2016). Does selfstigma reduce the probability of seeking mental health information?. Journal of Counseling Psychology, 63(3), 351-358. doi:10.1037/cou0000108

Lieberman, A. (1998). A perspective on infant mental health. The Signal, 6, 11-12. Retrieved from http://www.waimh.org/i4a/pages/index.cfm?pageid=3315.

Mukolo, A., Helfinger, C.A., \& Wallston, K.A. (2010). The stigma of childhood mental disorders: A conceptual framework. Journal of the American Academy of Child \& Adolescent Psychiatry, 49(2), 92-103. doi: 10.1097/00004583-202002000-00003

National Center for Child Traumatic Stress (2016). Welfare practice to improve placement stability breakthrough series collaborative: Promising practices and lessons learned. 
Further Consideration of Systems, Stigma, Trauma and Access to Care

(2013). Retrieved from

http://www.nctsn.org/sites/default/files/assets/pdfs/using_ticw_bsc_final.pdf

National Child Traumatic Stress Network (2008). Child welfare trauma training toolkit: Comprehensive guide-2nd edition. Retrieved from http://www.nctsn.org/nctsn_assets/pdfs/CWT3_CompGuide.pdf

National Child Traumatic Stress Network, Child Welfare Collaborative Group (2016). Traumainformed interventions. Retrieved from http://www.nctsn.org/resources/topics/child-welfare-system

Niederland, W. G. (1961). The problem of the survivor: The psychiatric evaluation of emotional disorders in the survivors of Nazi persecution. Journal of the Hillside Hospital, 10, 233247.

Owens, P. L., Hoagwood, K, Horwitz, S. M., Leaf, P. H., Poduska, J. M., Kellam, S. G., \& Lalongo, N. S. (2002). Barriers to children's mental health services. Journal of American Academy of Child Adolescent Psychiatry, 41:6. 731-738

Phelan, J., Link, B., Moore, R., \& Stueve, A. (1997). The stigma of homelessness: The Impact of the label "homeless" on attitudes toward poor persons. Social Psychology Quarterly, 60(4), 323-337. Retrieved from http://www.jstor.org/stable/2787093

Rogers, K.C., Bobich, M., \& Heppell, P. (2016). The impact of implementing an "Incredible Years" group within a family living unit in a transitional living shelter: The case of "Cathy." Pragmatic Case Studies in Psychotherapy, 12(2), Article 1, 65-112. Available: pcsp.libraries.rutgers.edu

Simon, V. A., Feiring, C., \& Cleland, C. M. (2016). Early stigmatization, PTSD, and perceived negative reactions of others predict subsequent strategies for processing child sexual abuse. Psychology of Violence, 6(1), 112-123. doi:10.1037/a0038264

Tjaden P., Thoennes, N. (2000). Extent, nature, and consequences of intimate partner violence: Findings from the national violence against women survey. Washington, DC: National Institute of Justice.

Van der Kolk, B.A., McFarlane, A.C., \& Weisaeth, L. (Eds.), (1996). Traumatic stress: The effects of overwhelming experience on mind, body, and society. New York: Guilford Press.

Weinreb, L. F., Buckner, J. C., Williams, V., \& Nicholson, J. (2006). A comparison of the health and mental health status of homeless mothers in Worcester, Mass: 1993 and 2003. Journal of Public Health. August, 96(8): 1444-1448.

Williams, M. (2016). Integrating early childhood mental health and trauma-informed care for families with young children. Pragmatic Case Studies in Psychotherapy, 12(2), Article 2, 113-123. Available: pcsp.libraries.rutgers.edu

Young, A. S., \& Rabiner, D. (2015). Racial/ethnic differences in parent-reported barriers to accessing children's health services. Psychological Services, 12(3), 267-273. doi:10.1037/a0038701

Zajac, K., \& Kobak, R. (2009). Caregiver unresolved loss and abuse and child behavior problems: Intergenerational effects in a high-risk sample. Development and Psychopathology, 21, 173- 187. 